VOL 4 (2020) NO 1

e-ISSN : 2549-9904

ISSN : 2549-9610

INTERNATIONAL JOURNAL ON INFORMATICS VISUALIZATION

\title{
A Proposed Framework for Fingerprint-based Voting System in Bangladesh
}

\author{
Nahida Nigar", Mohan Lal Nath", MD. Toufiqul Islam ${ }^{\#}$ \\ \# Computer Science and Engineering, Southern University Bangladesh, Chittagong, Bangladesh \\ E-mail:n.nigar.87@gmail.com,mohanvaiboss@gmail.com,toufiqulislam6051@gmail.com
}

\begin{abstract}
The objective of this project is to improve the existing voting system that will be accurate, transparent, and faster and will ensure a single vote for a single person. Our proposed system has covered all of these issues successfully. This product is affordable by many organizations where preferential elections conducted. The product is a prototype and can be implemented for vast use. Voting is an onerous task for the election commission to conduct free and fair polls in our country, the largest democracy in the world. A lot of money has been spent on this to make sure that the elections are rampage free. But, now- a -days it has become very usual for some forces to indulge in rigging which may eventually lead to a result contrary to the actual verdict given by the people. In order to provide inexpensive solutions to the above, this project is implemented with the biometric system i.e. fingerprint scanning. This is used to ensure the security to avoid fake, repeated voting, etc. It also enhances the accuracy and speed of the process. The system uses a thumb impression for voter identification as we know that the thumb impression of every human being has a unique pattern. Thus it would have an edge over the present-day voting systems. The purpose of such a system is to ensure that the voting rights are accessed only by a legitimate user and no one else. In this, creation of a database consisting of the thumb impressions of all the eligible voters in a constituency is done as a pre-poll procedure. During elections, the thumb impression of a voter is entered as input to the system. This is then compared with the available records in the database. If the particular pattern matches with anyone in the available record, access to cast a vote is granted. But in case the pattern doesn't match with the records of the database or in case of repetition, access to cast a vote is denied or the vote gets rejected. The result is instantaneous and counting is done. The overall cost for conducting elections gets reduced and so does the maintenance cost of the systems.
\end{abstract}

Keywords - Electronic Voting Machine (EVM), Microcontroller, Fingerprint Authentication, Central Integrated Database.

\section{INTRODUCTION}

Electronic Voting Machine (EVM) retains all the characteristics of voting by ballot papers while making polling a lot more expedient. Being fast and absolutely reliable, the EVM saves considerable time, money and manpower. And, of course, helps maintain total voting secrecy without the use of ballot papers.

The electronic voting machine has nowadays become an effective tool for voting. It ensures flawless voting and thus has become more widespread. It ensures the voting right of people. It avoids any kind of malpractice and invalid votes. Also such kind of system becomes more economical as consequent expenditure incurred on manpower is saved. It is also convenient on the part of voter, as he has to just press one key whichever belongs to his candidates.

Voting machines are the total combination of mechanical, electromechanical, or electronic equipment, that is used to define ballots; to cast and count votes; to report or display election results; and to maintain and produce any audit trail information. The first voting machines were mechanical but it is increasingly more common to use electronic voting machines.

A voting system includes the practices and associated documentation used to identify system components and versions of such components; to test the system during its development and maintenance; to maintain records of system errors or defects; to determine specific changes made after initial certification; and to make available any materials to the voter (such as notices, instructions, forms, or paper ballots). Traditionally, a voting machine has been defined by the mechanism the system uses to cast votes and further categorized by the location where the system tabulates the votes [8].

The objective of this project is to develop a preferential EVM with the following features: -

- This product should be low budget design

- The result of the product should be instantaneous

- It should be easy to maintain and operate. 
Different electronic voting machines have already been introduced previously to enhance the election process [2]-[5]. Some studies [4], [5] used Adhar card, conceptual design to link up the biometric data of Adhar card with e-voting machine. Sarkar et al. [2] provided a brief discussion of existing e-voting systems, framework, and protocols. Recent developments of EVM in context of Bangladesh has been discussed and suggested some strategies to improve the security, accuracy of the existing design. Yinyeh [10] provided a study of electronic voting the system in Ghana using biometric authentication which was implemented at each polling station over a local area network. A study conducted by Baig [9] discussed an e-voting system where smartphone application is used to give vote with $\mathrm{QR}$ code verification and this application uses the user information stored in Adhar card. Since the beginning, they were questionable because the technologists, as well as the community, noticed that they are losing their control through an essential part of the election process.

A quote linked to Stalin states that: "People who cast the votes decide nothing at all while the people who count the voters' votes decide everything." It is actually obvious that a great voting machine signifies a crucial component of a good democracy. Even though the repercussions of a not efficient electronic voting machine are not as easily obvious as those for train traffic control system or atomic energy plant control systems, they may be in the same way important, simply because the wellbeing of a community relies upon on them. Despite the fact that most critical systems are regularly examined and analysed for security and correctness electronic voting machine aren't exposed to the same level of analysis. A variety of latest researches have indicated that most or all of the electronic voting machine getting used these days is fatally defective and that their quality didn't fit the importance of the task they should to conduct. From this point of view, the most important task in creating and developing this project is to develop, enhance and improve the protection and the security of the voting system. This can be achieved by improving the safety measures by considering a variety of security actions and avoid the mistakes existing in previous machines.

\section{METHODOLOGY}

The methodology is the systematic, theoretical analysis of the methods applied to a field of study. It comprises the theoretical analysis of the body of methods and principles associated with a branch of knowledge. Typically, it encompasses concepts such as paradigm, theoretical model, phases and quantitative or qualitative techniques.

A methodology does not set out to provide solutions - it offers the theoretical underpinning for understanding which method, set of methods, or best practices can be applied to a specific case, for example, to calculate a specific result.

The aim and the objective are clearer due to the data and information has been gathered from the previous literature. The design model is the result of the hardware and programming integration. The design model shows the prototypes, elements, architecture, and components of the system. However, in order to make this project successful, the system must be well integrated and organized. The working process of our proposed framework is given below:

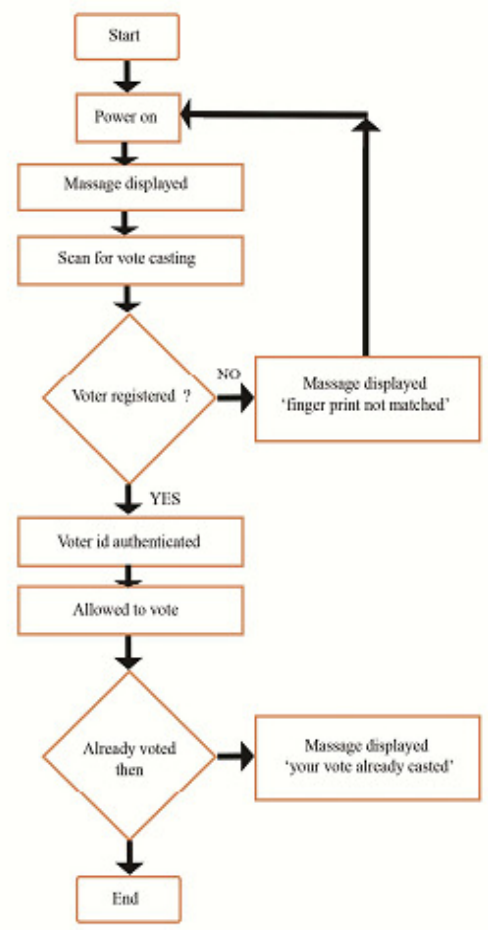

Fig. 1 Fingerprint voting machine system flow chart

\section{A. Electronic Voting in Bangladesh}

Electronic Voting Machine (EVM) is one of the leading products of Pi Labs Bangladesh Ltd. where EVMs, were made locally by the design and instruction of Election Commission (EC) and with the technical assistance of the Institute of Information and Communication Technology (IICT) of Bangladesh University of Engineering and Technology (BUET), and Bangladesh Machine Tools Factory (BMTF). The EC contracted out supplying the required number of EVM to IICT and BMTF. The initiative for making EVM is funded by the United Nations Development Program (UNDP). Following the specification [6], IICT and BMTF imported necessary materials from other countries to produce EVM. EC has calculated that initially, an individual EVM costs TK 24,000 to TK 30,000 to produce a single unit. At present, it takes about TK 45,000. For covering 41,000 polling stations in one-day national elections in Bangladesh, it might cost at about 46.12 million Taka (Bangladeshi currency) for producing 0.2 million EVMs. EC argues that although the cost of EVM the based election is initially high in comparison to a one-day election in a manual process, ultimately it is a costeffective device because it can be reused in further elections. As a result, EVM can save a huge amount of money as it does not require printing of ballot papers, buying of bags and other materials. Most importantly, EVM will give leverage to EC for better electoral management in terms of saving time at every level whether in preparing, conducting or result in processing. These voting machines are somewhat similar to India's EVMs in design and contain a control unit, ballot unit, and a display unit. The units are run by batteries and are connected to each other. Two major advantages of this machine are: (a). "There is no way to hack into the machines or rig the vote," and (b) No way to hack because it has no wireless connectivity or it is not a part of any network. 
Election Commission (EC) of Bangladesh had piloted these machines for vote capture with great success indifferent local government election in Bangladesh [2], [3].

Fig. 2 Electronic voting machine (EVM) in Bangladesh

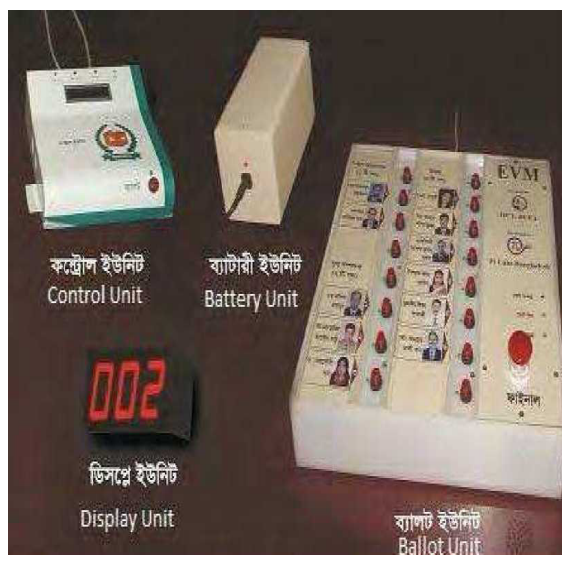

\section{B. Pilot Projects in Bangladesh}

For the first time in the country's history, the election commission of Bangladesh used 79 EVM (electronic voting machine) at 14 polling centers (all centers of a ward) while Chittagong City Corporation (ChCC) election was held on June 17, 2010. A total number of 25,230 voters showed up at the centers. The system has drawn the attention of many voters as it was an entirely new experience for them and

the process was quick and hassle-free. The whole process was completed within only two hours after the votes arrived as four votes cast per minute [7].

TABLE I

DETAIL INFORMATION OF LAST SiX ELECTIONS PERFORMED BY EVMS

\begin{tabular}{|l|l|l|l|l|l|}
\hline Year & $\begin{array}{l}\text { Election } \\
\text { Event }\end{array}$ & $\begin{array}{l}\text { Casted } \\
\text { Vote }\end{array}$ & $\begin{array}{l}\text { No of } \\
\text { EVMs }\end{array}$ & $\begin{array}{l}\text { Casted } \\
\text { votes by } \\
\text { EVM }\end{array}$ & Comments \\
\hline $\begin{array}{l}5^{\text {th }} \text { Jan, } \\
2012\end{array}$ & $\begin{array}{l}\text { Comilla City } \\
\text { Corporation }\end{array}$ & $\begin{array}{l}1,27,072 \\
(75 \%)\end{array}$ & $\begin{array}{l}421 \text { in } \\
65 \\
\text { polling } \\
\text { stations }\end{array}$ & -- & $\begin{array}{l}3 \text { out of } \\
421 \\
\text { EVMs } \\
\text { temporary } \\
\text { trouble }\end{array}$ \\
\hline $\begin{array}{l}17^{\text {th }} \\
\text { Jan } \\
2011\end{array}$ & $\begin{array}{l}\text { Narshingdi } \\
\text { Municipal }\end{array}$ & $\begin{array}{l}54,000 \\
(67.20 \%)\end{array}$ & $\begin{array}{l}198 \text { in } \\
31 \\
\text { polling } \\
\text { stations }\end{array}$ & $\ldots$ & $\begin{array}{l}\text { No } \\
\text { technical } \\
\text { fault }\end{array}$ \\
\hline $\begin{array}{l}17^{\text {th }} \\
\text { June } \\
2010\end{array}$ & $\begin{array}{l}\text { Chittagong } \\
\text { City } \\
\text { Corporation }\end{array}$ & $\begin{array}{l}8,55,064 \\
79 \text { in } 14 \\
\text { polling } \\
\text { stations }\end{array}$ & 25,230 & $\begin{array}{l}\text { No } \\
\text { troubles } \\
\text { with } \\
\text { EVMs }\end{array}$ \\
\hline $\begin{array}{l}30^{\text {th }} \\
\text { Oct } \\
2011\end{array}$ & $\begin{array}{l}\text { Narayangonj } \\
\text { City } \\
\text { Corporation }\end{array}$ & $\begin{array}{l}1,48000 \\
(69.92 \%)\end{array}$ & $\begin{array}{l}450 \text { in } \\
58 \\
\text { polling } \\
\text { stations }\end{array}$ & 4,00000 & $\begin{array}{l}\text { 2 out of } \\
450 \\
\text { EVMs } \\
\text { temporary } \\
\text { trouble }\end{array}$ \\
\hline $\begin{array}{l}20 \text { Dec } \\
2012\end{array}$ & $\begin{array}{l}\text { Rangpur City } \\
\text { Corporation }\end{array}$ & $\begin{array}{l}2,86,200 \\
(80 \%)\end{array}$ & $\begin{array}{l}30 \text { in } 4 \\
\text { polling } \\
\text { stations }\end{array}$ & 54000 & $\begin{array}{l}\text { Generally } \\
\text { peaceful } \\
\text { with } \\
\text { high voter } \\
\text { turnout }\end{array}$ \\
\hline $\begin{array}{l}\text { Dec } \\
30, \\
2018\end{array}$ & $\begin{array}{l}\text { Parliamentary } \\
\text { Elections }\end{array}$ & $\begin{array}{l}1.92 \\
\text { million } \\
(51.41 \%)\end{array}$ & $\begin{array}{l}5045 \text { in } \\
6 \\
\text { polling } \\
\text { station }\end{array}$ & 192000 & $\begin{array}{l}\text { Generally } \\
\text { peaceful } \\
\text { with } \\
\text { high voter } \\
\text { turnout }\end{array}$ \\
\hline
\end{tabular}

\section{A. Operation of Electronic voting Machine}

In our designed electronic voting machine, there are three units: control unit, ballot unit, an identification unit.

- In the control unit, there is an ON/OFF power switch.

- When the power switch is turned ON the LED glows of the control unit.

- Then we have to put a password to start the voting procedure.

- Four switches like the result, delete, lock, vote in four different modes are designed in a control unit. These switches are under the control of the voting authority.

- Fingerprint sensor identifying the voter fingerprint for authentication.

- By pressing the result switch, the results of individual candidates will be shown on the LCD display.

- When vote casting and vote calculation is totally completed, then by pressing the lock switch, all the results remain protected and then the power switch of the electronic voting machine will be OFF during the unexpected situation. Again when the situation becomes calm, then we can start our voting process performed by the electronic voting machine.

- By pressing the switch of voting mode on the control unit by the voting authority, the LED glows of the ballot unit, thus enables the voter to put his vote. 


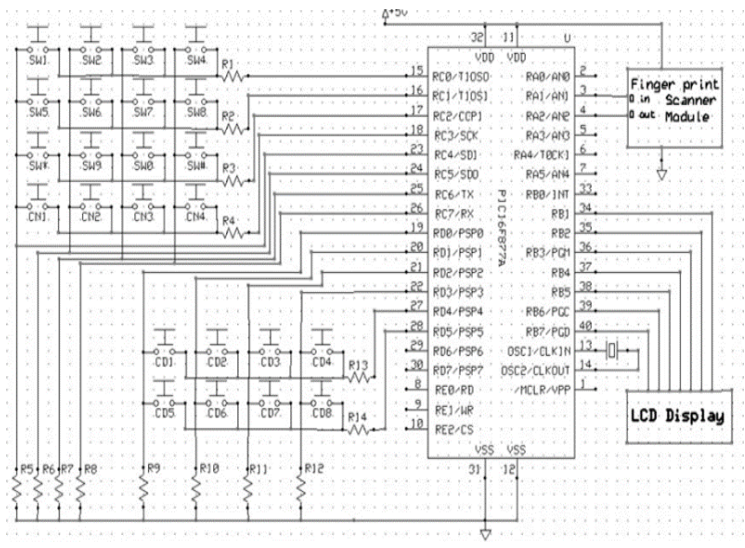

Fig. 4 Circuit Diagram of Electronic voting machine (EVM)

B. The layout of the EVM System

\begin{tabular}{||l|l|}
\hline \hline Ballot Unit \\
\hline \hline Candidate 01 \\
\hline \hline Candidate 02 \\
\hline \hline Candidate 03 \\
\hline \hline Candidate 04 \\
\hline \hline Candidate 05 \\
\hline \hline Candidate 06 \\
\hline \hline Candidate 07 \\
\hline \hline Candidate 08 \\
\hline \hline
\end{tabular}

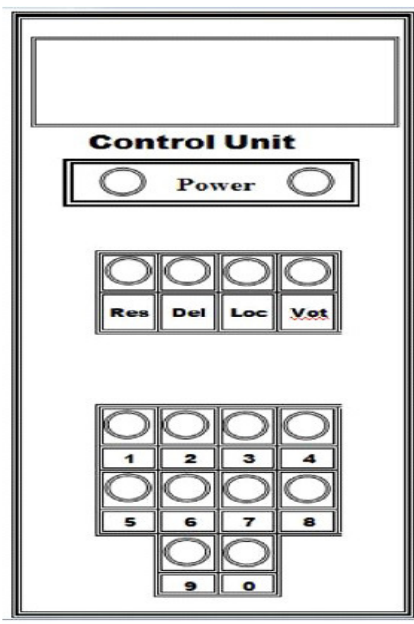

Fig. 5 Overview of Electronic voting machine (EVM)

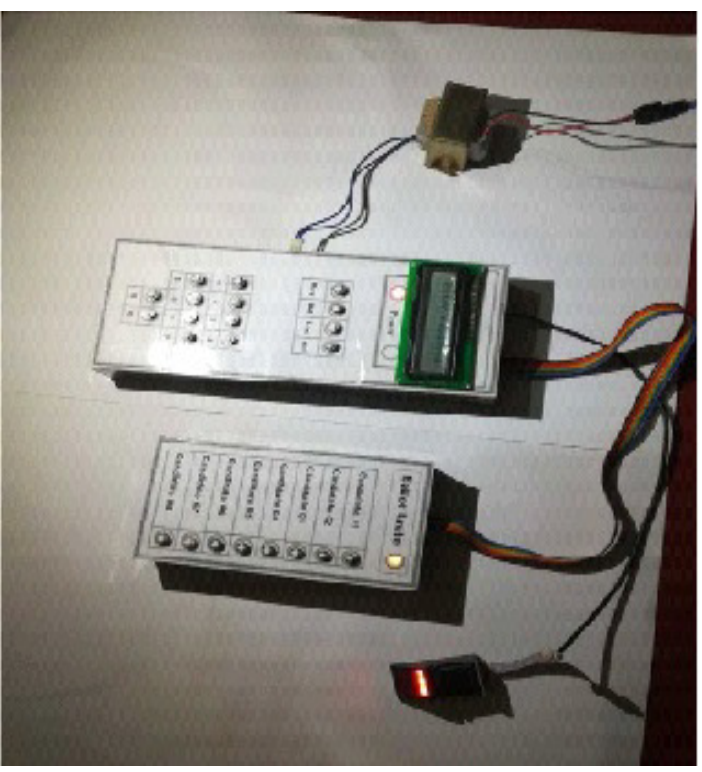

Fig. 6 Outlook of Electronic voting machine (EVM)

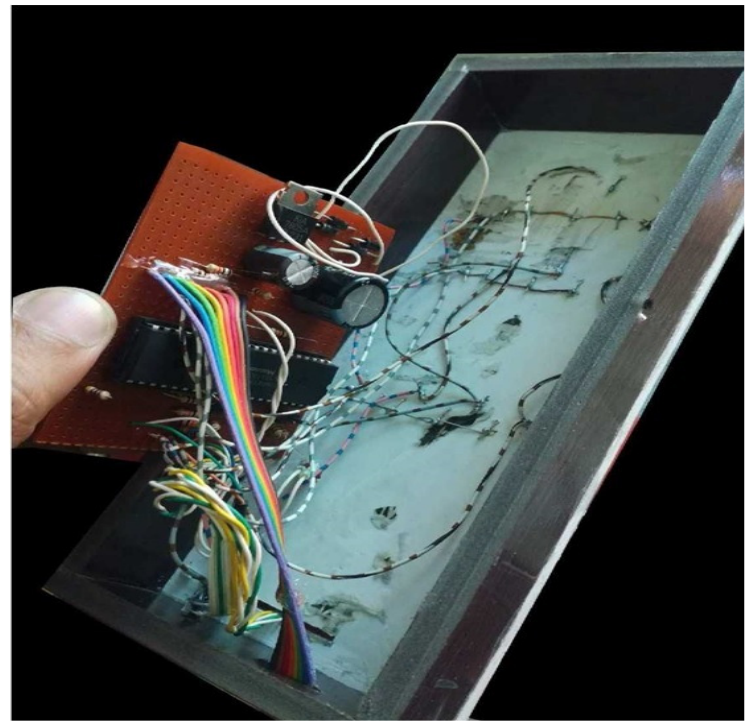

Fig. 7 The internal figure of Electronic voting machine (EVM) TABLE III

LIST OF COMPONENTS AND COST ANALYSIS

\begin{tabular}{|l|l|l|l|}
\hline SI No. & $\begin{array}{l}\text { Component } \\
\text { Name }\end{array}$ & Quantity & $\begin{array}{l}\text { Price } \\
\text { (Taka) }\end{array}$ \\
\hline 1 & $\begin{array}{l}\text { Microcontroller } \\
\text { (PIC16F877A) }\end{array}$ & 1 & 300 \\
\hline 2 & $\begin{array}{l}\text { LCD Display } \\
\left(16^{*} 2\right)\end{array}$ & 1 & 350 \\
\hline 3 & $\begin{array}{l}\text { Finger print } \\
\text { Sensor }\end{array}$ & 1 & 6000 \\
\hline 4 & Transformer & 1 & 250 \\
\hline 5 & $\begin{array}{l}\text { Crystal } \\
\text { Oscillator } \\
\text { (4MHz) }\end{array}$ & 1 & 30 \\
\hline 6 & Touch Switch & 22 & 110 \\
\hline 7 & Resistor (1k,10k) & 15 & 15 \\
\hline 8 & $\begin{array}{l}\text { Voltage } \\
\text { Regulator }\end{array}$ & 1 & 20 \\
\hline 9 & LED & 2 & 10 \\
\hline 10 & Vero board & 1 & 30 \\
\hline 11 & Lead & 2 Yrd & 40 \\
\hline 12 & Misc. & all & 350 \\
\hline $\begin{array}{l}\text { Total } \\
\text { Cost }\end{array}$ & & & $\mathbf{7 5 0 5}$ \\
\hline
\end{tabular}

\section{RESULT AND DISCUSSION}

The sequence of the FPVM processing system organized as follows: we need to assemble the system with PCB. After assembling this machine with power line then we need to switch on. The FPVM consists of a controller and switching unit, both the units are works independently and in collaboration with each other as well.

After switching on, the display shows the message 'Enter Password'. Then after given the password, this voting machine automatically prepared itself to voting mode. Then the display shows the massage for casting vote Then the fingerprints scanner accepting the command from Control Unit to collect the fingerprints of a voter. 


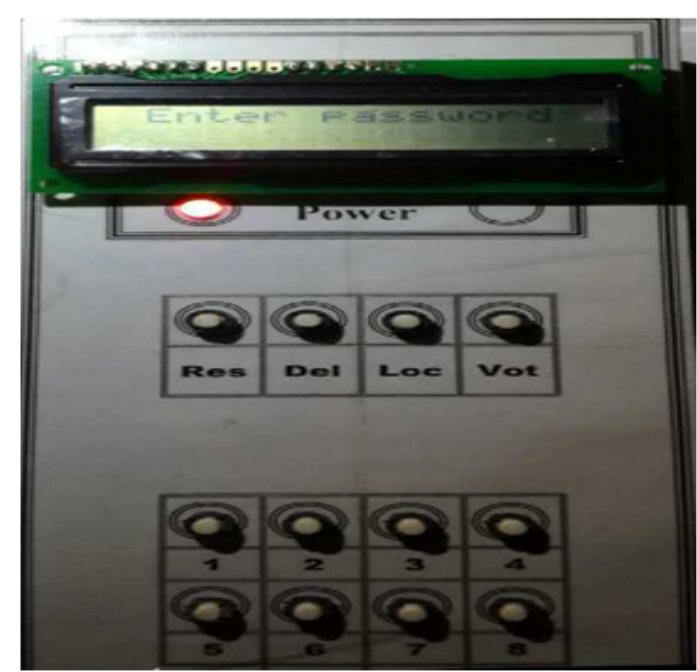

Fig. 8 Voting System Power ON

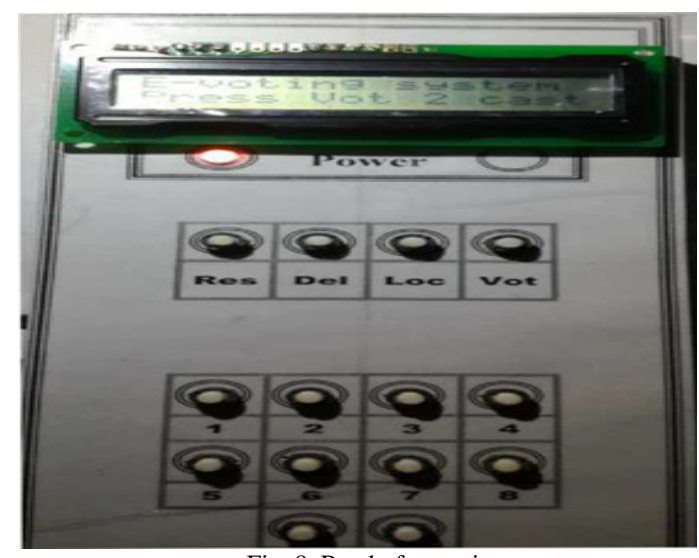

Fig. 9 Ready for casting a vote

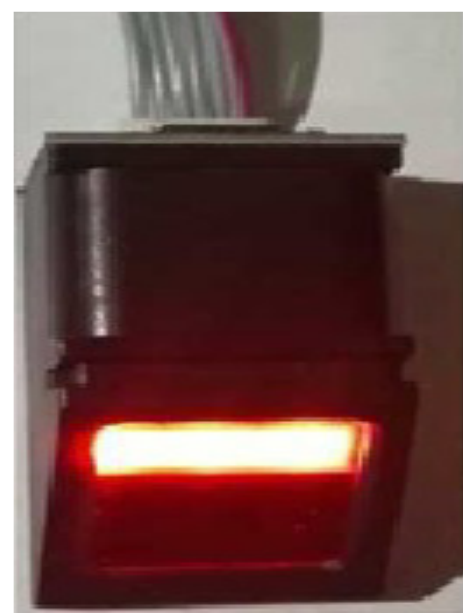

Fig. 10 Scanner Switches ON

- The Control Unit is accepting fingerprints in enrolling mode and is responding accordingly.

- In identifying and vote casting mode, the CU checks for fingerprint detection routine.

- In identifying and vote casting mode, CU communicates with switching unit in order to exchange various signals to the ballot unit.
- $\mathrm{CU}$ is counting the votes for individual candidates and the total number of votes cast can be cheeked at any time.

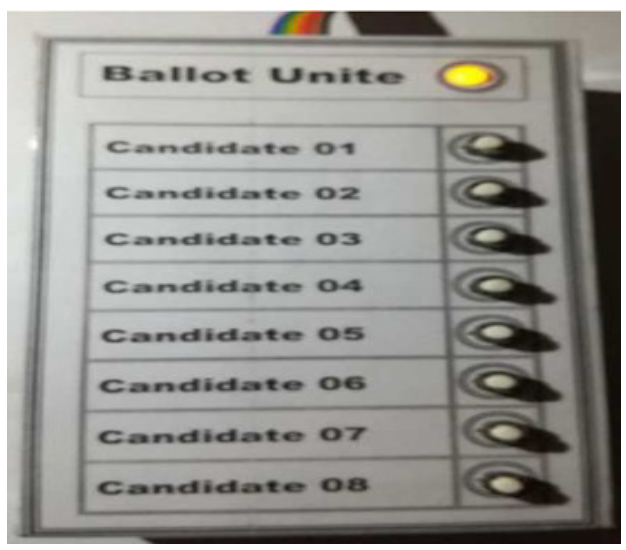

Fig. 11 Ballot Unit

- In result mode, the CU displays the votes of individual candidates, in consecutive order whenever the "result button is pressed".

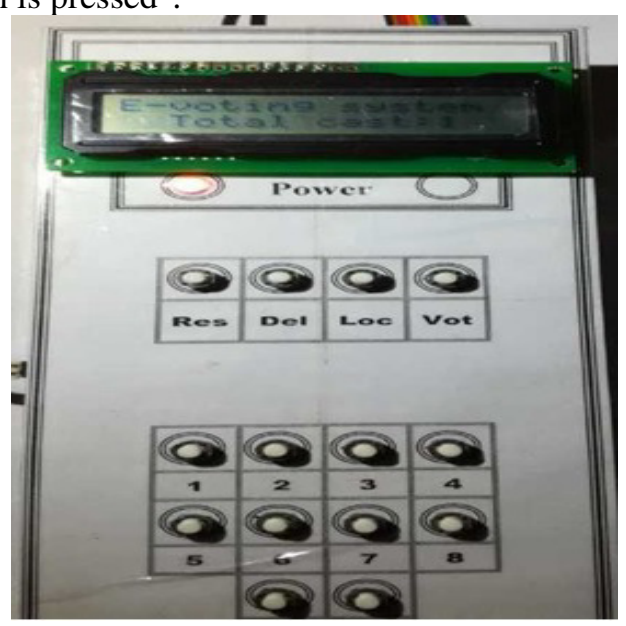

Fig. 12 Voting Result

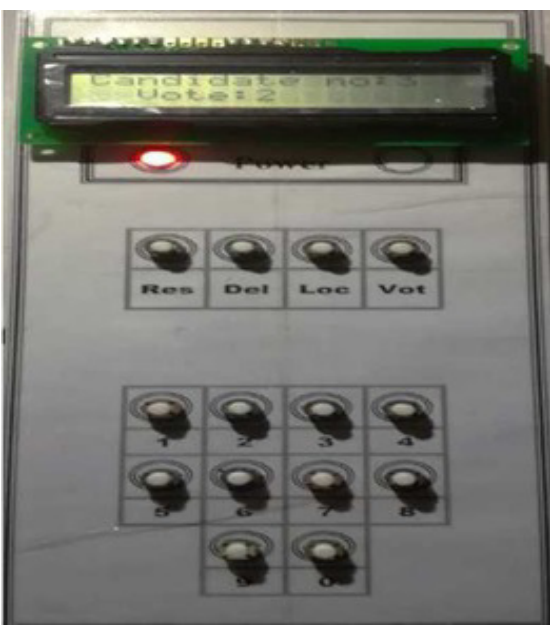

Fig. 13 Separate Voting Result of each candidate

- The total number of votes can be cheeked in result mode. Then easily can choose the winner.

In total, the complete system is working as per the initial specification and requirements of our project. Because of the creative nature of the design and due to lack of time, some 
feature could not be fine-tuned and are not working properly. So certain aspects of the system can be modified as operational experience is gained with it.

\section{A. Authenticate Result}

In FPVM, it can be authenticated automatically, because in this voting machine it stored all the voters' information. When the voter pressed the scanner it collects the fingerprints and automatically shows the information of voter on the display.

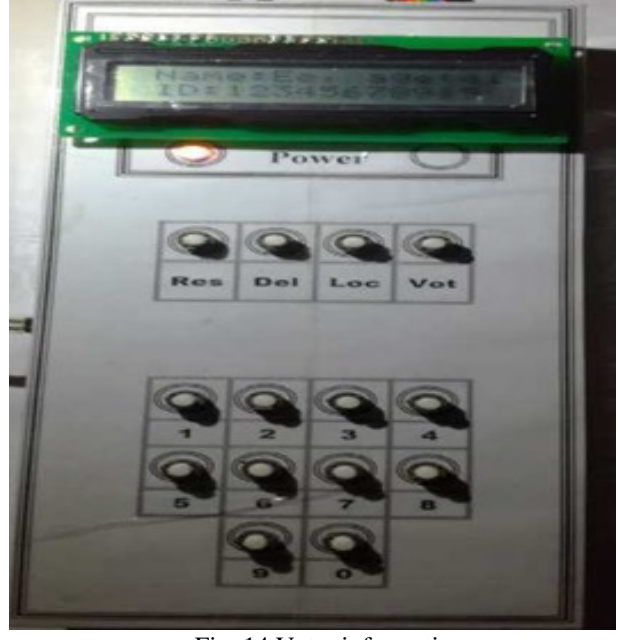

Fig. 14 Voter information

And for that reason only registered voter can give the vote in this machine otherwise an unregistered voter cannot be given the vote.

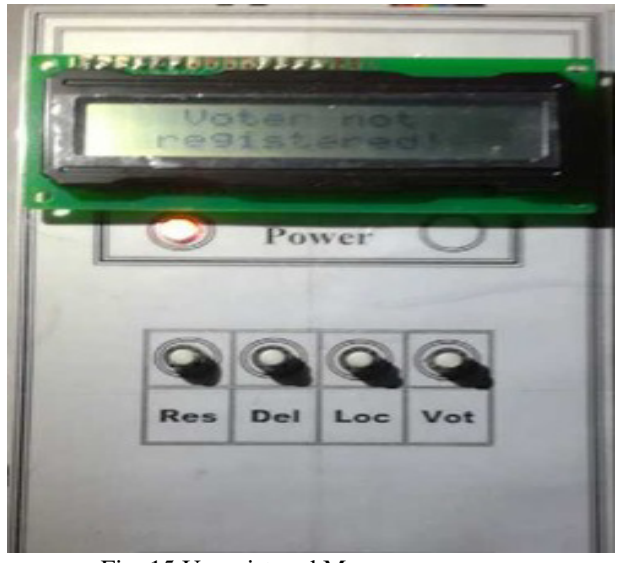

Fig. 15 Unregistered Message on screen

If this voter gives the vote then it will not be casted and the machine shows a message (like this "voters fingerprint not matched") in the screen. So false voter can be easily indicated by this machine. And also it doesn't be allowed the same fingerprint. If a voter gives the vote before then he cannot be given vote again, if he does this then voter will be caught easily.

\section{CONCLUSIONS}

In big elections there are a huge number of people want to cast their votes, in order to avoid the congestion at the voting point there is need to provide a number of personal computers each one will be connected to the main computer/server in order to allow many people to perform voting at the same time and prevent congestion.
Fingerprints considered as one of the most popular biometric methods used for human recognition. Every person in the globe is born with unique fingerprint even twins born with totally different fingerprints and fingerprint is naturally unchangeable throughout life. For that reason, we tried to use a biometric voting system using fingerprint thus a person ID has been made with his finger print. This fingerprint voting system is implemented and evaluated successfully.

To test the system strength and weakness we need to evaluate the performance of the system using different PCs with different specification.

Our proposed voting system is accurate, transparent, and faster and will ensure a single vote for a single person. This product is a prototype and affordable by many organizations where preferential elections conducted. Moreover, this system will provide a feasible and reliable voting process. Better database maintenance, automated registration system and the process of casting vote using fingerprint will further help us to fulfill our purpose.

\section{ACKNOWLEDGMENT}

The author would like to appreciate the effort from editors and reviewers. This research did not receive any specific grant from funding agencies in the public, commercial, or not-forprofit sectors.

\section{REFERENCES}

[1] M. M. Sarker and M. N. Islam, "Management of sustainable, credible and integrated electronic voting (e-voting) system for bangladesh," Management of Sustainable Development, vol. 5, no. 1, pp. 15-21, 2013.

[2] Sarker, M. Mesbahuddin, et al. "An approach of automated electronic voting management system for bangladesh using biometric fingerprint." International Journal of Advanced Engineering Research and Science 3.11 (2016)

[3] Iswarya, Deepika, Rathna Prabha, and Trini Xavier. "A Survey on EVoting System Using Arduino Software." International Journal of Advanced Research in Electrical, Electronics and Instrumentation Engineering (An ISO 3297: 2007 Certified Organization) 5.2 (2016): 687-690.

[4] KARTHEEK, THAMPULA, and B. NAVEEN KUMAR. "Biometric Based Secured Electronic Voting Machine." (2016)

[5] Raj, Rakesh S., et al. "An online voting system using biometric fingerprint and Aadhaar card." IJCAT International Journal of Computing and Technology 1.4 (2014): 87-92.

[6] D. Tribune, EC publishes roadmap, says use of EVMs still possible, July 16, 2017 [Accessed October 06, 2017]. [Online]. Available:http://www.dhakatribune.com/bangladesh/politics/2017/07/1 6/ec-lays-path-11th-national-elections/.FLEXChip Signal Processor (MC68175/D), Motorola, 1996.

[7] J. U. Md. Meftaul Islam, Dept. of International Relations, EVM and Digital Bangladesh, 2011 (accessed Sep 22, 2017). [Online]. Available: http://www.thedailystar.net/news-detail-215643A. Karnik, "Performance of TCP congestion control with rate feedback: TCP/ABR and rate adaptive TCP/IP," M. Eng. thesis, Indian Institute of Science, Bangalore, India, Jan. 1999.

[8] Technovelgycom, Biometric identification systems, [Accessed October 02, 2017]. [Online]. Available: http://www.technovelgy.com/ct/Technology-Article.asp?ArtNum=12

[9] Baig, Hidayat, Taslim, B. Jeba, Rajesh, A. Prof., J., and Prof., "Secured evoting via smart phone app," International Journal on Future Revolution in Computer Science Communication Engineering (IJFRSCE), vol. 2, pp. 20-23, 2016.

[10] M. Yinyeh and K. Gbolagade, "Overview of biometric electronic voting system in ghana," International Journal of Advanced Research in Computer Science and Software Engineering, vol. 3, no. 7, 2013.. 